\title{
\#CONECTE-SE, PARTICIPE E APRENDA HISTÓRIA: RELAÇÕES ENTRE JUVENTUDE E CONHECIMENTO HISTÓRICO NO ESPAÇO ESCOLAR EM CONTEXTOS URBANOS
}

\author{
\#CONNECT, PARTICIPATE AND LEARN HISTORY: RELATIONSHIPS \\ BETWEEN YOUTH AND HISTORICAL KNOWLEDGE IN URBAN SCHOOL \\ CONTEXTS
}

\author{
CABRAL, Maria Aparecida ${ }^{1}$
}

\begin{abstract}
RESUMO
O presente artigo apresenta resultados preliminares obtidos com a execução do projeto submetido à Faperj em 2017, intitulado História.com: ensino de história, fontes documentais e historiografia, voltado à inserção de estudantes do Ensino Médio em atividades científica na área da História, bem como problematiza os usos políticos das diversas mídias comunicativas, redes sociais e tecnologias da informação e comunicação (TICs) nas atividades formativas do ensino do conhecimento histórico escolar, realizados pelos jovens participantes durante os encontros de orientação. Focaliza-se um conjunto de práticas construídas nesse contexto formativo, em que a colaboração, a empatia e o protagonismo desses sujeitos tornam-se elementos fundamentais para se pensar novas perspectivas para 0 ensino e a aprendizagem da história escolar.
\end{abstract}

Palavras-chave: História ensinada; Jovens talentos; Tecnologia; Aprendizagens significativas; Redes sociais.

\begin{abstract}
The present article shows preliminary data from the project "History.com: history teaching, documentary sources and historiography" submitted to FAPERJ in 2017. It addresses the insertion of High School students in scientific activities in the area of History. It also discusses the political uses of various communication media, social networks and information and communication technologies (ICTs) in History educational activities academic advisory meetings. It focuses on a set of practices built in that formative context, where the collaboration, empathy and protagonist of those subjects are fundamental for thinking new perspectives for teaching and learning history at school.
\end{abstract}

KeYwORDS: History teaching; Young talents; Technology; Significant learning; Social networks.

\footnotetext{
${ }^{1}$ Professora Adjunta do Departamento de Ciências Humanas, na disciplina de Estágio Supervisionado na Licenciatura em História e do Programa de Pós-graduação em Ensino de História da UERJ, Mestrado Profissional em Rede Nacional (Professora História). e-mail: cidacabral4567@gmail.com
} 
DOI: $10.12957 / \mathrm{e}-m o s a i c o s .2018 .33424$

\section{INTRODUÇÃO}

Nas últimas décadas no Brasil tem crescido a preocupação entre os professores de História, pesquisadores das Ciências Humanas e educadores sociais a respeito da aprendizagem significativa, bem como das potencialidades das tecnologias de informação e comunicação - as denominadas TICs - nos processos de ensino e aprendizagem do conhecimento escolar. A maneira como a juventude contemporânea tem interagido com as diversas mídias digitais no espaço escolar, e para além dele, no processo de aquisição de informações e sua respectiva apropriação também tem se constituído em uma questão relevante para todos aqueles que se voltam à tarefa do ensino no tempo presente, apontam algumas das recentes pesquisas no campo da educação e da historiografia sobre a história ensinada na escola.

As perguntas sobre como e de que forma os professores dessa disciplina podem instigar os seus alunos durante suas aulas? Ou quais as potencialidades dos ferramentais digitais na construção do conhecimento histórico escolar? São algumas das indagações que me sensibilizam para pensar o ensino e a aprendizagem do conhecimento histórico escolar, cuja finalidade é a compreensão da complexidade que envolve a construção de uma aula de História pelo professor de educação básica. Nessa direção, apresentamos neste artigo uma reflexão sobre as relações que podem ser construídas entre a juventude e o conhecimento histórico como o foco no uso político das mídias digitais, redes sociais, tecnologias da informação e comunicação nos encontros formativos, ocorridos no espaço escolar.

A problematização posta acima foi delineada no âmbito da realização do Projeto de Pesquisa, intitulado História.com: ensino de história, fontes documentais e historiografia, direcionado à inserção de jovens do matriculados em escolas públicas estaduais do Rio de Janeiro, em atividades de pesquisa, e quevisa à construção de práticas investigativas e científicas no campo da História, com a realização de seleção de fontes documentais acerca da História do Brasil, abarcando o recorte temporal de 1822 a 1988, referente à temática da cidadania articulada à construção do imaginário político, bem como o da cultura histórica.

Trata-se, aqui, de uma abordagem que considera o jovem como protagonista no processo de construção do conhecimento, com plenas condições de se apropriar das diversas ferramentas digitais e redes sociais. Entretanto, a realização de um projeto com esse propósito, implica em fazer um exercício de compreender quem são esses sujeitos, que acessos têm aos bens culturais e materiais, e não menos importante, entender com quais referenciais de conhecimento operam em seus percursos de aprendizagem, na aquisição do conhecimento.

Para isso, buscamos dialogar com as recentes publicações no campo do ensino de história, que têm primado por enfatizar o papel dos jogos didáticos e eletrônicos em sala de aula, o uso das múltiplas linguagens, a construção de ferramentas digitais 
por parte de alunos e professores etc, no processo de ensino e aprendizagem da história escolar. (ARRUDA, 2013; CAIMI, 2014; SEFFNER, 2013; ROCHA, 2014) na estruturação da fundamentação desta discussão. Cabe ressaltar que estas leituras contribuem não somente para pensar a relevância social de tais temáticas e suas metodologias, no contexto atual da sala de aula, mas, sobretudo, oferecem subsídios e referenciais teórico-metodológicos em uso no campo do ensino de história, além de mostrar um panorama bastante denso a respeito das tendências e perspectivas para a história escolar.

\section{"HISTÓRIA ENSINADA" OU "HISTÓRIA ESCOLAR": PESQUISA E ENSINO NO TEMPO PRESENTE}

Nos últimos anos as investigações na área do ensino de História têm crescido significativamente tanto no campo da Educação, quanto na História privilegiando temáticas sobre a formação docente, a construção do currículo, as políticas educacionais, os processos de ensino e aprendizagem, os materiais didáticos, os patrimônios materiais e imateriais, as diversidades culturais e sociais etc. Certamente, o fortalecimento do Ensino de História pode ser atribuído na atual conjuntura pela presença de pesquisadores em todas as regiões brasileiras, que promovem debates e reflexões sobre os processos de ensino e aprendizagem da história escolar ${ }^{2}$ com a proposição de eventos científicos-acadêmicos.

Desde os anos de 1990 as pesquisas a respeito das potencialidades de fontes históricas no ensino e aprendizagem da história escolar têm sido agregadas a esse rol de assuntos, constituindo-o em um objeto de pesquisa bastante recorrente entre os pesquisadores do ensino de História. Constata-se que de lá para cá houve não somente um ampliação dos referenciais teórico-metodológicos nas pesquisas sobre os processos de ensino e aprendizagem no campo da história escolar, a partir das interlocuções com autores da História Cultural, da Teoria da História e do Campo da Sociologia do Currículo, assim como o da História da Educação, que possibilitaram a renovação de estudos nessa área, mas principalmente a constituição de um nova forma de se investigar a produção, a circulação e os usos de diversos suportes na difusão do conhecimento histórico ao público escolar e em geral.

De modo geral, tais trabalhos têm focalizado a introdução de novas temáticas a partir das demandas legais (Leis 10.639/03 e 11.645/08), com o estudo da introdução de novos conteúdos escolares na síntese histórica do Brasil e do Mundo.

\footnotetext{
${ }^{2}$ Quando fazemos uso dos termos "história escolar", "ensino de história", "história ensinada" nos referimos à história ensinada no âmbito da instituição escolar brasileira. São designados aqui para o entendimento de um conjunto de práticas disciplinares, voltado ao ensino do conhecimento histórico de natureza escolar, sem nenhuma pretensão de tecer quaisquer questionamentos acerca dos usos e concepções dessa terminologia nas pesquisas recentes construídas no campo do ensino de História no Brasil.
} 
Nessa direção, justificamos a relevância de um projeto voltado à promoção de pesquisas de cunho histórico entre jovens inseridos no ensino médio, pois cada vez tem se instituído a necessidade de inserção de fontes documentais na realização das aulas de história, na educação básica de modo. Trata-se, desse modo, proporcionar aos estudantes a vivência de experiências significativas na construção e apropriação dos procedimentos básicos da construção do conhecimento histórico, específicos do ofício do historiador.

Nessa perspectiva, os trabalhos de Silva e Fonseca (2011) têm contribuído para novos entendimentos em torno dos saberes e fazeres docentes nas aulas de História. Ao investigarem temas sobre a formação de professores de História e o trabalho desenvolvido na educação básica, a maneira como se dão os critérios organizativos dos currículos escolares em relação ao conhecimento histórico no século XX, a importância dos diferentes suportes de aprendizagem no contexto de ensino e aprendizagem da história escolar e os impactos da tecnologia nas formas de ensinar e aprender esse conhecimento na contemporaneidade, esses autores evidenciam uma crescente preocupação dos pesquisadores com as questões prementes que permeiam o campo do ensino de História no Brasil.

$\mathrm{Na}$ seara da história escolar, podemos afirmar que, desde o processo de redemocratização do ensino nos anos de 1980 a proposição de um ensino de história problematizador, isto é, que leve à construção de uma visão crítica dos processos sociais, tem mobilizado o campo dos historiadores, que atuam na educação básica a refletir acerca das linguagens e metodologias de ensino, que possibilitam a transmissão do saber histórico escolar às futuras gerações, além dos próprios professores que ministram essa disciplina.

A adoção dessa perspectiva no ensino de História tem se mostrado como uma possibilidade interessante aos alunos por vários motivos. Dentre eles, destacamos o fato de que os conteúdos históricos são vistos como construções sociais, frutos de embates políticos e resultantes das concepções de cada tempo e espaço uma vez que há a possibilidade de se pesquisar diversas informações sobre o mesmo acontecimento social.

Nesse sentido, compreendemos que o uso das diversas ferramentas online pode instrumentalizar os alunos da educação básica para as práticas de pesquisa de fontes documentais disponibilizadas na rede virtual, à medida que propicia o desenvolvimento de competências relacionadas à observação, análise, classificação de informações e produção de escritas.

As produções recentes no campo da História Digital e também da História Pública têm propiciado debates promissores acerca dos processos de produção do conhecimento histórico e seus processos de difusão e apropriação entre os historiadores, professores de história e o público em geral. Estas, certamente, estão se inter-relacionando e/ou conectadas com os saberes produzidos por professores e alunos em situação de ensino e aprendizagem da história de natureza escolar. 
Pesquisas realizadas no âmbito da educação e também no campo da História, no início do século XXI, demonstram que o ensino de História tem sido um campo fértil e promissor na construção de novas práticas, tanto do ponto de vista da inovação pedagógica, criando espaços de discussão e debates entre alunos e professores no momento da construção do conhecimento, quanto da problematização acerca do conhecimento histórico legitimado socialmente.

Seffner (2013, p. 50-51) afirma que as aulas de História são excelentes oportunidades para a realização uma aprendizagem significativa aos alunos, mas para isso ocorrer torna-se necessário o estabelecimento de critérios por parte dos docentes. Em sua opinião:

o ensino de História é um ensino de situações históricas. Mais do que nomes, datas e acontecimentos, o professor deve propiciar ao aluno a compreensão de como se estrutura uma dada situação, seja ela de revolução, eleição, 'descoberta', guerras, (...).

Em um texto recente acerca dos fazeres de três professoras de educação básica, em suas aulas de História para adolescentes e jovens, de uma escola pública de São Gonçalo, a pesquisadora Helenice Rocha (2014) destaca o uso de fontes diversificadas no processo de ensino e aprendizagem de um conhecimento histórico, tido muitas vezes como muito distante da realidade deles, como uma possiblidade de uma aprendizagem significativa de história. Bittencourt (2004), por sua vez, chama atenção em suas investigações para a centralidade das fontes documentais na constituição do saber histórico escolar. Em sua visão, tais documentos podem ser considerados pelos professores como ricos materiais didáticos no processo de ensino e aprendizagem da história escolar.

No âmbito das pesquisas sobre as metodologias da história escolar, essa autora argumenta que as investigações que focalizam as fontes documentais, possibilitam o entendimento de que os vestígios localizam-se em diferentes lugares, são produtos de uma certa memória social e necessitam de "ser preservados como patrimônio da humanidade". Nessa direção, podemos afirmar que uso de fontes documentais diversificadas, tais como: fotografias, imagens, depoimentos orais, patrimônios histórico-culturais, canções musicais, produção cultural, indumentária, alimentos, mapas históricos, documentos pessoais e privados (cartas, e-mails, diários, cadernos de anotações etc) dentre outras, têm sido extremamente valorizadas pelos professores de educação básica, tornando-se recursos didáticos potentes na problematização das diversas temporalidades, dos valores e da compreensão das mudanças e permanências no processo histórico.

O que podemos apreender dessas leituras é que cada vez mais se advoga em prol da necessidade de inserção de fontes documentais na realização das aulas de 


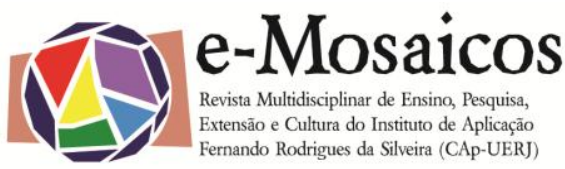

DOI: $10.12957 /$ e-mosaicos.2018.33424

história, na educação básica de modo a proporcionar que os estudantes construam uma bagagem conceitual e metodológica que lhes permita a apropriação dos procedimentos básicos da construção do conhecimento histórico, específicos do ofício do historiador.

\section{Projeto História.com: enSino de históRIA, FONTES documentais E HISTORIOGRAFIA}

Esse projeto de pesquisa destina-se à inserção de jovens do ensino médio em práticas científicas no campo da História, com a priorização de levantamento e análise de fontes documentais disponibilizadas em suportes digitais, livros didáticos, arquivos etc com o foco na questão da cidadania no processo de formação sóciohistórica brasileira, abarcando o recorte temporal de 1822, - momento em que o Brasil se torna uma nação independente - , até 1988, ano em que foi promulgada a Constituição Cidadã - , consolidando os direitos sociais básicos no país.

Com vistas a instigar em estudantes de Ensino Médio, dos primeiros e segundos anos, um olhar problematizador aos processos de construção do conhecimento histórico escolar, por meio de coleta e análise de fontes documentais contidas em diversos suportes de aprendizagem (livros didáticos, revistas especializadas na área de História e na web), delineamos como procedimento de atuação a construção de situações de ensino e aprendizagem, que proporcionem a construção de novos entendimentos e percepções acerca dos processos políticos e históricos instituídos no Brasil a partir de sua Independência.

Cabe enfatizar que, as discussões em torno da construção de práticas exitosas no campo do ensino de história têm sido recorrentes em diversas publicações voltadas aos professores de educação básica há pelo menos últimas três décadas, nos encontros acadêmico-científicos e nos cursos de formação de professores, também são frequentemente objetos de debates e intervenções; sendo indicadores de uma preocupação com a aprendizagem da história entre crianças, adolescentes e jovens matriculados nas escolas de educação básica. Ainda assim, transformar o ensino de história dotado de sentido ao público escolar tem sido um enorme desafio aos professores e pesquisadores dessa área.

Desde o início dos anos de 1980, quando o ensino da história escolar passou por uma grande revisão quanto à proposição de temas, abordagens e metodologias de ensino, criou-se certo consenso nessa área de conhecimento sobre a importância do uso de fontes documentais nas aulas. (ABUD; SILVA; ALVES, 2010; BITTENCOURT, 2004; URBAN \& LUPORINI, 2015). Por meio da problematização de documentos históricos, visamos propiciar que os estudantes do Ensino Médio participantes do Programa Jovens Talentos, vinculados a este projeto de pesquisa, se apropriem de procedimentos e metodologias construídos no campo da História com a promoção de pesquisas em suportes digitais ou impressos, instigando-os a pensarem historicamente. Três objetivos específicos apresentam-se articulados entre si e 
relacionam-se a esse objetivo principal, a saber: reconhecer que a história na escola pode ser trabalhada por meio de evidências (registros escritos, imagens, objetos, paisagens etc); valorizar operações cognitivas voltadas à capacidade de extrair e correlacionar informações dessas evidências contribuindo para a construção de práticas científicas no trato da história escolar e converter alguns temas que são familiares nas aulas de história da educação básica em problemas historiográficos em relação com a produção no campo da História.

Certamente, a construção de experiências significativas no campo da aprendizagem em História, com a promoção de ambientes propícios à pesquisa e investigação de fontes documentais relacionadas à temática articuladora deste projeto, e em diálogo com a produção historiográfica acerca dos processos de construção da cidadania no Brasil, pode contribuir para nova maneira de conceber o ensino de História na escola.

Com início em agosto de 2017, as ações concebidas para o desenvolvimento desse projeto voltaram-se para a organização de reuniões de trabalho com os jovens, levantamento, com seleção e classificação de fontes documentais para análise, definição de roteiros de leituras, pesquisa em materiais informativos em diversos suportes físicos e virtuais. Preliminarmente, investimos em nossa comunicação por meio do grupo de WhatsApp (Grupo Jovens Talentos - História Adino Xavier) criado para a troca de mensagens, a disponibilização de materiais, os esclarecimentos de dúvidas, a apresentação de propostas de reuniões etc, e também mensagens eletrônicas por e-mails, pois acreditamos que estes meios potencializam a nossa forma de diálogo, isto é, a nossa interação, colocando-nos em uma situação de colaboração constante.

Apesar de o nosso projeto não ser direcionado à História Digital, compreendemos que há conexões com essa abordagem teórico-metodológica no campo da História, pelo fato de pretendermos investir na construção de um Blog ou página de Facebook, produção de mídias diversas que serão disponibilizadas em rede social, com a finalidade de apresentar os resultados dos projetos de trabalhos desses alunos, a partir da pesquisa de fontes documentais diversas.

O fato de esse projeto ser construído para um público juvenil implicou na construção de uma metodologia de trabalho, que busque interfaces com os saberes destes jovens no campo da informática, das redes sociais e das mídias digitais. A mudança nos suportes de informação no tempo presente, tem nos obrigado (na condição de professores e pesquisadores do ensino de história), a nos preocupar com os processos de aprendizagens. Sobretudo, a pensar não somente na ampliação de locais, mas, principalmente, nas formas de armazenamento e disponibilização de fontes documentais históricas. 


\section{ENSINO DE HISTÓRIA, REDES SOCIAIS E FERRAMENTAS DIGITAIS NO PROCESSO DE ENSINO E APRENDIZAGEM}

Criar meu web site Fazer minha home-page com quantos gigabytes

Se faz uma jangada Um barco que veleje (Gilberto Gil, 1998)

Selecionamos um pequeno trecho da música, composta por Gilberto Gil, nos anos de 1990, citado acima, para iniciar a discussão sobre a presença da tecnologia, redes sociais, Facebook, WhatsApp, Internet em nosso fazer como professores e pesquisadores do campo de ensino de História no Brasil, pois as ideias contidas em tal fragmento são indícios interessantes de como as ferramentas digitais, a comunicação em rede, e a constante divulgação dos fazeres ordinários não somente se estabeleceram em nossas vidas, mas tornaram-se uma necessidade vital aos indivíduos contemporâneos. Estas não só criam novas relações, mas impactam diretamente em nossas percepções de mundo e, por essa razão, vêm sendo objetos de análises entre os pesquisadores das Ciências Humanas e Sociais.

Alguns autores têm evidenciado o surgimento, a partir da segunda metade do século $X X$, de uma modificação profunda nos suportes de informação, seja por sua imensa capacidade de transmissão a um número muito grande de pessoas, o que lhe confere um certo dinamismo, seja pelo seu caráter de armazenamento de textos, imagens e vídeos. Fenômeno esse que demarca os significados e os sentidos atribuídos à aprendizagem da cultura impressa em relação aos produzidos atualmente pelos suportes digitais. (CAIMI, 2015; POZO,2002).

A sociedade contemporânea impõe um ritmo de aprendizagem cada vez mais veloz, o que nos obriga a pensar de forma distinta do que tradicionalmente se convencionou por ensino e aprendizagem. Nas instituições escolares, por sua vez, professores se veem demandados por uma geração que solicita agilidade nos processos comunicacionais, porque não pode perder tempo.

A tecnologia, especificamente, a informática tem representado uma transformação radical no modo como os indivíduos lidam com as informações, alterando, sobretudo, a relação entre eles. Ao considerar esse fenômeno bem característico do século XXI, é perceptível de se observar a extrema valorização dos saberes produzidos, no tocante ao uso do computador, da internet e seus sites, pela atual sociedade do conhecimento.

Na era digital novas formas de produção, circulação e difusão da informação são construídas, implicando em uma nova relação do leitor (usuário) com os textos

\footnotetext{
${ }^{3}$ Letra da música Pela Internet, de Gilberto Gil.
} 
DOI: $10.12957 / \mathrm{e}-m o s a i c o s .2018 .33424$

eletrônicos. Segundo Chartier (2009, p. 59), "a textualidade eletrônica de fato transforma a maneira de organizar as argumentações, históricas ou não, e os critérios que podem mobilizar um leitor para aceitá-las ou rejeitá-las".

A problematização dos usos que os professores e alunos da educação básica têm realizado no ambiente escolar e além dele nos remete a pensar em alguns desafios, que estão postos à educação escolar nesse cenário tão marcado pela provisoriedade do conhecimento, e de busca incessante por informações. O que está em jogo, portanto, não é o ensino e aprendizagem a partir da utilização da internet, assim como das demais ferramentas virtuais na sala de aula pelos alunos, mas sim a capacidade que estes têm de selecionar o que é relevante para a sua formação ou quiçá para a sua vida.

A internet, as redes sociais, as mídias digitais oferecem uma gama de possibilidades para o desenvolvimento educativo de jovens na atualidade. A complexidade que envolve a discussão sobre os modos como as mídias digitais, jogos eletrônicos (em redes) e demais ferramentas online podem contribuir na aprendizagem da História, tem sido objeto de muitos investigadores no campo do ensino da história escolar. Nessa direção, as pesquisas de Arruda (2013) têm trazido uma contribuição significativa para a discussão sobre as potencialidades formativas dos jogos digitais, especialmente, os videogames que simulam acontecimentos históricos.

Caimi (2014), em recente artigo sobre os novos suportes de informação e a aprendizagem histórica na escola, chama a atenção para a forma como os jovens atuais lidam com os múltiplos recursos tecnológicos. Essa autora tomando por base algumas das reflexões de Veen e Wrakking (2009), que nomeiam a geração atual de Homo Zappiens, entende que essa nova geração, "atua em uma cultura cibernética global com base na multimídia". (VEEN e WRAKKING apudCAIMI).

De acordo com Veen e Wrakking (2009) apud Caimi (2014, p. 167), esses jovens da geração Homo zappiens têm uma relação muito particular com a instituição escolar, diferindo-a das gerações anteriores. Destacam-se alguns comportamentos,

a) Reconhece a escola como um dos interesses, entre muitos outros, como rede de amigos, trabalho de meio turno, encontros sociais; $b$ ) considera a escola desconectada de seu mundo e de sua vida cotidiana; c) demonstra comportamento ativo, em alguns casos hiperativo; d) concede atenção ao professor por pequenos intervalos de tempo; e) quer estar no controle daquilo com que se envolve e não aceita explicações do mundo apenas segundo as convicções do professor; f) aprende por meio dos jogos, de atividades de descoberta e investigação, de maneira colaborativa e criativa. 
Quando a autora faz esse alerta, mobilizando os trabalhos de Veen e Wrakking (2009), certamente, almeja apresentar alguns (dos muitos) desafios prementes ao nosso fazer docente, principalmente, na história escolar. Para Caimi (2014, p. 168), trata-se de investir na construção de novos olhares acerca da geração Homo zappiens, pois o que está em questão é a análise por parte dos professores das "possibilidades formativas subjacentes ao uso de alguns suportes de informação, tomados (ou não) na condição de fontes para o estudo da história escolar".

Nessa sociedade marcada pela instantaneidade aliada a ideia de provisoriedade do conhecimento, ensinar História torna-se desafiante aos professores dessa disciplina, uma vez que esse saber é compreendido pela maioria dos estudantes como um conhecimento muito distante de sua prática, logo, desnecessário. A pergunta sobre o como a aula de História pode ser instigante aos estudantes da educação básica, permitindo-lhes a construção de novos olhares acerca de diferentes realidades em diferentes temporalidades e espaços, tem acompanhado investigadores que tem se dedicado à investigação no campo do ensino de História.

\section{APONTAMENTOS PRELIMINARES SOBRE O CONTEXTO DE PRODUÇÃO DAS FALAS E ESCRITAS DOS JOVENS NO ÂMBITO DO PROJETO}

Quem trabalha com jovens em idade escolar aprendeu por força da experiência, que a criação de um espaço de "fala" e de "escuta" é muito importante no momento das aulas. Visa senão somente para se aproximar da turma de alunos, mas, sobretudo, o aprimoramento do ato de ensinar, dotando-o de sentidos e significações para todos os sujeitos envolvidos. Nessa direção, a criação de espaços oportunos para a participação de estudantes que convide-os a interagir, questionar e propor resoluções acerca dos assuntos em pauta, podem se tornar caminhos instigantes na construção do conhecimento histórico escolar, porque rompem com as tradicionais hierarquizações nas relações escolares, fortemente atreladas às estruturas de poder, cada vez mais em xeque nos cotidianos escolares.

Solicitar aos jovens que exponham publicamente suas opiniões, ou até mesmo seus entendimentos acerca de um determinado assunto, não é uma tarefa tão simples assim! Em espaços grandiosos como o da sala de aula, a produção da fala coloca-os em evidência, em um grupo que tece comentários, faz julgamentos, numa fase da vida que muitos deles desejam estar em grupos e ser aceitos por essas comunidades, mas sem passar por tamanha exposição. Compreender como as culturas juvenis são (con)formadas no tempo presente e, sobretudo, como estas forjam determinados comportamentos entre o público juvenil, pode ser uma chave interessante para perceber a complexidade das relações sociais travadas no interior das instituições educativas. 
Mesmo considerando todos esses condicionantes sociais, que determinam as posições sociais, que ora silenciam o sujeito, ora o expõem, por meio da fala, isto é, da argumentação, apostamos em práticas que valorizam a construção dos discursos, emissão de enunciados, como estratégias de empoderamento do público juvenil. Nessa compreensão, o espaço da fala dos jovens que participam desse projeto tem sido bastante valorizado a cada encontro, que dura em torno de três horas semanais.

Suas posições e opiniões são consideradas e valorizadas, ainda assim são objetos de questionamentos e intervenções tanto de nossa parte, como da dos demais participantes do projeto. Salientamos que a maneira como esses jovens têm construído seus argumentos na exposição das tarefas que lhe são incumbidas, aprimora-se a cada instante, pois estes se preparam para o momento da apresentação de seus respectivos apontamentos acerca das fontes documentais interpretadas, dos textos selecionados e lidos.

Assumindo o caráter de centralidade da linguagem na difusão e apropriação do conhecimento escolar, Maria Lima destaca a importância de investigações, seja no campo educacional, ou da historiografia que tematizem as práticas discursivas dos sujeitos em processo de ensino e aprendizagem. Defende a autora, que os discursos são constituintes do conhecimento e "podem nos fornecer elementos para compreender os mecanismos do processo de aprendizagem para além do mero domínio de dados e informações disciplinares" (LIMA, 2009, p. 214-215).

A produção de atividades escritas sobre os entendimentos individuais desses jovens acerca dessa experiência de participação no projeto tem sido um caminho no que temos investido, na busca da construção de um conhecimento escolar significativo. Assim, como uma atividade de campo realizado no mês de novembro no Cais do Valongo, região central e portuária do Rio de Janeiro, tombado como Patrimônio Histórico da Humanidade, em julho de 2017, pela Unesco, na Pedra do Sale no Instituto de Pesquisa e Memória dos Pretos Novos - IPN ${ }^{4}$.

Antes dessa visita que contou ainda com a presença da professora de História da escola, além da nossa companhia em todo o percurso, houve uma introdução sobre a temática da escravidão no Brasil, com ênfase na discussão sobre o conceito de cidadania e concepção de direito nas diferentes temporalidades na História do Brasil. Essa conversa preliminar foi balizada pela leitura de textos informativos curtos, bem como a visualização de dois filmes de curta duração, disponíveis no sítio do YouTube.

Podemos inferir que essa experiência foi marcante, pois participaram de todo o roteiro programado com muito entusiasmo e dedicação. A oportunidade de

\footnotetext{
${ }^{4}$ Tal visitação que fez parte da programação de um XI Encontro Nacional de Pesquisa em Ensino de História - ENPEH, sediado na Universidade Federal do Rio de Janeiro - UFRJ, contando com a exposição dos Professores Doutores Amilcar Araújo, da Faculdade de Educação - FE- UFRJ e Mônica Lima, do Instituto de História- IH-UFRJ, ambos vinculados a essa instituição.
} 
vivenciar uma atividade fora dos muros escolares, e em outro município possibilitou que esses jovens aprendessem de uma maneira diferente, isto é, pelo conhecimento do patrimônio material e imaterial, por meio da visitação. Suas produções escritas acerca da vivência e problematização dessa temática sinalizam um aspecto muito interessante sobre a apropriação acerca das relações historicamente construídas no Brasil entre os períodos: colonial e imperial, e com permanências e consequências sociais até os dias atuais. Outro elemento significativo que se fez marcante nessas escritas autorais foi a visita ao Instituto de Pesquisa e Memória dos Pretos Novos, as narrativas apontam indícios de o quanto os jovens ficam impactados quando sabem da existência do cemitério dos pretos novos, da forma como os escravos eram tratados, da destinação dos seus corpos e pelas constantes tentativas de apagamento dessa história. Observamos que há uma tentativa constante por parte desses jovens em compreender como foi possível a existência de tais relações.

A escrita nesse projeto adquire uma dimensão criativa e autoral. Acreditamos que ela tem o potencial de organização da construção do pensamento, em forma de linguagem, mas constitui-se como um lugar privilegiado porque permite ao estudante (autor) a mobilização de ferramentas conceituais e procedimentais na elaboração de sua narrativa histórica.

\section{CONSIDERAÇões FinAIS, OU O INÍCIO dE UMA NOVA CONVERSA....}

A análise apresentada mostra indícios de como trabalhos voltados à pesquisa histórica, que primem pela construção de práticas significativas aos seus participantes, podem contribuir no avanço de uma compreensão do entendimento do conhecimento histórico como um saber datado socialmente e construído pelo historiador a partir de referenciais teórico-metodológicos específicos desse campo. A partir da investigação da temática da cidadania, em diferentes temporalidades, a ser iniciada, preliminarmente com o levantamento de fontes documentais, e, em segundo lugar, com a instituição de seu tratamento crítico, e, finalmente, a construção de uma ferramenta online para a disponibilização do material produzido.

Ao fazermos usos das diferentes ferramentas digitais como uma forma rápida de acesso à informação, criamos a possibilidade de estreitamento da comunicação. Essa opção possibilitou, de um lado, que adentrássemos um universo promissor e instigante quanto à multiplicidade de dispositivos, que garantem a nossa conexão a tudo que é lançado na rede social, em um espaço bastante curto de tempo. Porém, de outro lado, nos obrigou a pensar nos usos políticos e sociais, que precisamos fazer de tais tecnologias. É inegável, que a participação em grupos através do aplicativo WhatsApp, que possibilita uma rápida e eficiente comunicação, o compartilhamento de áudios, vídeos, mensagens textuais, imagens etc apresenta novos horizontes de atuação entre aqueles que têm a incumbência de ensinar e os que estão na condição de aprendizes. 
São justamente esses aspectos multifacetados das redes sociais e das diversas ferramentas digitais, que em muitos casos, se mostram como dispositivos naturalizados, despossuídos de quaisquer intencionalidades políticas, uma vez que fazem presente no imaginário social, como entretenimento, e são usados frequentemente pelos jovens estudantes, que tentamos problematizar e pautar no desenvolvimento desse projeto, em busca de um ensino de história problematizador, que prime por um aprofundamento conceitual e metodológico.

A experiência com os jovens participantes do projeto História.com: ensino de história, fontes documentais e historiografia tem nos mostrado, que é possível construir uma relação diferente com as diversas tecnologias de informação e comunicação, ultrapassando, portanto, a ideia da interação e suas implicações sociais como mera expressão do consumismo contemporâneo.

\section{REFERÊNCIAS}

ABUD, Kátia; SILVA, André Chaves de Melo; ALVES. Documentos escritos e o ensino de História. In: . Ensino de História. São Paulo: Cengage Learning, 2010. p.126.

ALMEIDA, Anita Correia Lima de; GRINBERG, Keila. As WebQuests e o ensino de História. In: ROCHA, Helenice; MAGALHÃES, Marcelo; GONTIJO, Rebeca (Orgs.). $A$ escrita da história escolar. memória e historiografia. Rio de Janeiro: FGV, 2009. p. 201-212.

ARRUDA, Eucídio Pimenta. Cultura e Ensino de História na perspectiva das redes sociais e do Ciberespaço. In. BERETA, C; ZAMBONI, E. (Org.) Ensino de História, memórias e culturas. $1^{\mathrm{a}}$ ed. Curitiba, PR: CRV, 2013. p. 35-53

BITTENCOURT, Circe Maria Fernandes. Aprendizagens em História. In: Ensino de História: fundamentos e métodos. São Paulo: Cortez, 2004. p. 183-221.

CAIMI, Flávia. Geração Homo zappiens na escola: os novos suportes de informação e a aprendizagem histórica. In: MAGALHÃES, Marcelo; ROCHA, Helenice et ali. Ensino de História: usos do passado, memória e mídia. Rio de Janeiro: FGV, 2004. p.165183.

CHARTIER, Roger. A história ou a leitura do tempo. Belo Horizonte: Autêntica, 2009.

LIMA, Maria. A expressão linguística dos saberes: aspectos da relação entre a aprendizagem da língua escrita e o desenvolvimento da consciência histórica. In: ROCHA, Helenice A. B.; MAGALHÃES, Marcelo; GONTIJO, Rebeca. A escrita da história escolar: memória e historiografia. Rio de Janeiro: FGV, 2009. p. 213-245. 
POZO, Juan I. Aprendizes e mestres: a nova cultura da aprendizagem. Porto Alegre: Artmed, 2002.

ROCHA, Helenice A. B. A presença do passado na aula de história. In: MAGALHÃES, Marcelo; et ali. Ensino de História: usos do passado, memória e mídia. Rio de Janeiro: FGV, 2014. p. 33-52.

SILVA, Marcos; FONSECA, Selva Guimarães. Ensinar história no século XXI: em busca do tempo entendido. 4. ed. Campinas, São Paulo: Papirus, 2011.

SEFFNER, Fernando. Aprendizagens significativas em História: critérios de construção para as atividades em sala de aula. In. GIACOMONI, Marcello P.; PEREIRA, Nilton M.; Jogos e Ensino de História. Porto Alegre: Evangraf, 2013. p. 47-62.

URBAN, Ana Claúdia; LUPORINI, Teresa Jussara. Aprender e ensinar história nos anos iniciais do Ensino Fundamental. São Paulo: Cortez, 2015.

Recebido em 02 de Abril de 2018 Aceito em 30 de Maio de 2018 